\title{
Secrets in the Classroom: Self-Disclosure about Sexual Abuse
}

\author{
Ginger R. Gerrish1, Zackary Philyaw², Keisha E. Payne², Jerome Rabow², \\ Manpreet Dhillon Brar ${ }^{2}$ \\ ${ }^{1}$ Temple University, Philadelphia, PA, USA \\ ${ }^{2}$ University of California, Los Angeles (UCLA), Los Angeles, CA, USA \\ Email: jrabow@soc.ucla.edu
}

Received 30 May 2016; accepted 9 July 2016; published 12 July 2016

Copyright (C) 2016 by authors and Scientific Research Publishing Inc.

This work is licensed under the Creative Commons Attribution International License (CC BY). http://creativecommons.org/licenses/by/4.0/

(c) (i) Open Access

\begin{abstract}
This paper examined the self-disclosures of students about sexual abuse and assault in a university classroom. These self disclosures were secrets that prevented students from knowing and understanding their deeper selves. We described the structure of a university classroom that encouraged the revelation of secrets in the classroom. The self reported feelings of the seven individuals who revealed secrets, as well as interviews and web posts about the consequences for each individual were the basis of this paper. The classroom factors that facilitated disclosure along with positive benefits of disclosure were discussed.
\end{abstract}

\section{Keywords}

Secrets, Self-Disclosure, Mental Health, Psychosocial Adjustment, Shame, Abuse, Sexual Assault

\section{Introduction}

Secrets have received only slight empirical attention from modern sociologists despite the critical role they play in social relationships. As early as 1906, Simmel presented a "sociology of secrecy," describing it as a distinctively human trait (pp. 445). Classical sociologists like Marx and Weber have noted the importance of secrets: Weber observed the importance of secrets as a means for preserving power (Weber, 2002), while Marx believed that those who held power needed to keep the truth away from those with less power (Marx, 1899). Among modern sociologists, Goffman emphasized the importance of secrets for preserving cooperation, maintaining a performance, and preserving the special bonds between performers. Furthermore, Goffman detailed dark secrets, which might never be disclosed to the audience; strategic secrets, which could be disclosed when the perfor- 
mance was completed; and inside secrets, which defined the members of the group but which were neither dark nor strategic (Goffman, 1959). The work of these sociologists focuses on the importance and consequences of secrets for the collective. When we examine the role of secrets that individuals hold, a different picture emerges.

The major work on secrets held by individuals has been done by Loevinger and Blasi (1976). Secrets can prevent the individual from knowing their true self. The self that is hiding secrets from the world is protected by a feeling of shame. This shame prevents the individual from discovering their true self.

In the world of children, secrets can be magical, intimate, positive, and a haven from a world they cannot understand. Secrecy provides protection and preservation. Unfortunately, children can also hold dark secrets (Goffman, 1959). Childhood victims of physical or sexual abuse keep their experiences secret, preserving the shame associated with the self outlined by Loevinger and Blasi (1976). Childhood secrecy can endure into adult secrecy, a cycle that can be interrupted by self-disclosure.

\section{Revealing Secrets: Self-Disclosure}

Social psychologists have focused on self-disclosure in the context of personal relationships because the process increases the depth of connection and furthers empathy and intimacy. In larger groups, self-disclosure has been identified as a critical component in building cohesion, but the majority of studies have used therapeutic groups as the basis for investigation (Alcoholics Anonymous, 1990; Empey \& Rabow, 1961). Meta-analyses have found psychological benefits of self-disclosure, including less distress, negative affect, and depression (Frattaroli, 2006), whereas withholding secrets is associated with poorer psychosocial adjustment and the physical experience of being weighed down (Frijns \& Finkenauer, 2009; Slepian et al., 2012). In another meta-analysis of 205 studies, women were found more likely to reveal secrets than men (Dindia \& Allen, 1992). Further research by Won-Doornink reveals that individuals self-disclose more frequently to those they like, increasing their own likeability after self-disclosing. These self-disclosures vary in their degree of intimacy, are related to the stage of a relationship and to the reciprocity of self-disclosure. Less intimate self-disclosures occur at the beginning of the relationship and more intimate disclosures increase over time (Won-Doornink, 1985). In this paper, we focus on the more intimate self-disclosure of sexual abuse.

Disclosures related to sexual abuse have been studied in families (Grambling, Carr, \& McCain, 2000) and primarily focus on females, although important work has begun with male survivors of sexual abuse and the challenges of disclosure (Sorsoli, Kia-Keating, \& Grossman, 2008). When we seek to discover the amount of self-disclosure for childhood sexual abuse we find that $20 \%$ never disclosed the abuse, with men less likely than women to have told anyone (Hébert, Tourigny, Cyr, McDuff, \& Joly, 2009). Work on university teaching suggests that intimate disclosures in the classroom setting can be both challenging for the instructors and students and beneficial for academic understanding (Rosenbloom \& Fetner, 2001). Nicole Bishop has challenged the value and growing trend of personal disclosures by students. She argues that while studies suggest that selfdisclosures about sexual abuse can provide benefits on a macro level (the class), the micro level consequences for individuals who disclose in the classroom remains largely unknown. She urges us to recognize that, "the liberty and autonomy of students is threatened by being "compulsorily appraised, evaluated and rated". The larger the scope for teacher appraisal, the larger the scope for ill-judged paternalism is, for the abuse of personal information, for errors of judgment and the operations of favoritism and bias that may blight a student's prospects (Bishop, 1996: p. 433). Her admonitions need to be taken seriously and the authors of this paper have sought to do so.

This study seeks to evaluate the decision and consequences of self-disclosure of sexual abuse by five women and two men in an upper division undergraduate honors class, as well as the effects on interpersonal and intrapersonal relations.

\section{Methods}

We examine the process of deciding to self-disclose about sexual abuse and assault by employing the theoretical framework of Rosenbloom and Fetner (2001). The teaching employed in this class sought to personalize the learning experience by connecting students' experiences with concepts and theories discussed in the classroom. This pedagogy has proven useful for discussing traditionally "taboo" topics (Rosenbloom \& Fetner, 2001: p. 440), has an extensive history in the academy and is now being integrated with Transformative Pedagogy (Rabow \& Yeghnazar, 2009a; Dhillon, Rabow, Han, Maltz, \& Moore, 2014; Rabow, Dhillon, \& Payne, 2015). 
This study examines an honors class in a major public university in the fall of 2012 that consisted of about thirty students. The class was designed to introduce students to the inequalities perpetuated within the public education system. Readings focused on classroom, curriculum, and teacher practices that reinforced the inequalities that perpetuated racism, sexism, and homophobia. The instructional team consisted of a white professor and two former students, an African American and Indian woman, who co-facilitated the class. This added diversity to the teaching team in gender, race and age. Prior instruction established that course material is made more meaningful when students are able to connect these to their own personal experience through discussion and writing (Dhillon et al., 2014; Han et al., 2015). Instructors believed this would occur if students felt they could freely express their thoughts, feelings, and beliefs about the educational process, their own education, and their beliefs about fellow students ${ }^{1}$.

Students begin the class with limited knowledge of what the class is about. The choice to enroll is based on a broad outline the students can read in advance, the convenience of the hour, or a recommendation from a friend or peer. During the first two days of the class, the instructor emphasizes the importance of responding to ideas and readings at a personal level. Numerous activities predispose students toward internalizing and personalizing the material. These include writing four web posts per week, that are not monitored by instructors, a small group discussion format (Rabow \& Yegnazar, 2009b); and guided exercises that are aimed at revealing some of the more personal dimensions that students hold, including stereotypes and social class beliefs (Rabow, Dhillon, \& Payne, 2015). During the beginning of the class, students explore the themes of racism and sexism and self-disclose about personal experiences related to these topics. For example, one Latina student talked about the many fellow students who were shocked to discover that she did not get into UCLA because of affirmative action. A male black student reported an instance in which he visited a white male professor's office hours and was immediately greeted with "I guess you are one of the people who did poorly on the exam.” These early self disclosures of events related to racism primed later self-disclosures regarding sexism, sexual abuse and assault that occurred throughout the second part of the course. Lastly, a final dimension to the pedagogy involves the instructors encouraging all students to respond openly but respectfully to classmates and materials. There was no pressure on students if they wanted to maintain silent. The goal is to have every student express their personal beliefs, values, biases and stereotypes, in an atmosphere that simultaneously encourages self-examination. The self-disclosure from one of the co-instructors, who revealed an experience with sexual abuse, contributed to the classroom culture that encouraged self-examination.

\section{Preparation for Disclosure}

The decision to disclose is a multifaceted process unique to each individual. Despite the unique details of each disclosure, the factors that students cited as predisposing them to disclose can be classified into four categories which emerged from a careful reading of the interviews. These categories include environmental factors, intrapersonal factors, relational factors, and combinational factors.

Environmental factors refer to the structural components of the course rather than tangible items. Such factors include group setting (small v. large), role of instructor (authority v. ally), and the creation of a safe place as well as trust.

Intrapersonal factors are thoughts and actions that belong exclusively to the discloser. These factors involve an internal reflection through which the individual attempts to justify the decision to disclose based upon the relevance of their disclosure to other stories shared and the risks/consequences associated with disclosure (i.e. shame, judgment from others, pity).

Relational factors include the group dynamic of the classroom that motivates and in some cases compels individuals to disclose. There emerged a sense of belonging to the group and a responsibility which students felt on account of group membership. It should be noted that there are instances in which relational factors refer specifically to a particular student-student or instructor-student relationship.

Rather than understanding combinational factors as two simultaneously occurring factors, a more accurate description is that the presence of one factor may trigger another factor or that one factor can evolve into another. This complexity of factors attempts to capture the multifaceted process of the decision to disclose.

${ }^{1}$ A detailed description of the pedagogy is described in: Dhillon, Moore, Rabow, \&Vega, 2013. 


\section{Results}

\subsection{Environmental Factors}

Each of the seven students in the study cites at least one environmental factor as a part of his or her preparation for disclosure. One female student, Rachel, identifies the classroom setting as a place where trust has been established. More importantly, she explains that the process of building that kind of an environment is a "progression," and is a necessary process in order to prepare students to disclose intimate details in the classroom:

"I think it's really good. But I think that you can't just do it from- I think there has to be a progression, you can't just on the first day of class, "Tell us about your rape story." They're not gonna say anything, they're gonna think you're weird. I don't think that would be very effective. I think it's good, its just the method of going about it is very important. You have to establish trust and you have to have open minds and that might take a couple of weeks so I don't think you should do it right away. But I think it's a really good idea." (white female)

In this case, a history of trust appears to be a crucial past of cultivating an appropriate environment for disclosures. Brian also comments on this gradual building of trust:

"Had it not built up gradually, I probably would have just run out of the class. If we had just dived in headfirst it would have been just too much for me to handle because I'm not used to sharing with people." (white male)

For Marcus, environmental factors appear to have influenced the disclosure process early on. He describes the classroom as a "safe space" to share and mentions that before the introduction of this kind of an environment, he felt that suppressing his emotions regarding his secret was his only option:

"It was weird because I felt comfortable doing it in that venue and with those people because so many people had been exposed to these deep feelings. It felt like a safe space and I had never had that before. Before the pushing away of those emotional things was a necessity." (African-American male)

Marcus expresses his surprise over feeling comfortable in that particular classroom space-what now seems like the requisite that previously prevented him from disclosing. For Marcus, the environmental factor (a "safe space”) marks the onset of his preparation to disclose.

Environmental factors proved similarly important in Marissa's preparation for disclosure. She explains that because of the "comfortable" environment that had been established, sharing her personal story of sexual abuse didn't seem out of context:

"Everyone else was sharing, that made me feel more comfortable. And the expectation was that we were supposed to share, not that I did it to meet anybody's expectations, but what I'm trying to say is that, it wasn't like they were getting something other than what they thought they were going to get. It wasn't left field and it wasn't off topic. So, everybody was sharing; it was really nice to sit around in a group with other females talking about things that most females would understand. The other things that other people were saying, that was very comforting and it made me feel comfortable." (white female)

For Brittany, the environmental factor in her preparation for disclosure appears to be rooted in what she perceived to be a unique opportunity:

"Yes and then also it was like, this might- I might never get this time again and I want to participate and I want to engage and so that's why I decided to share." (Middle Eastern female)

This classroom environment created a feeling within Brittany that motivated and prepared her to disclose.

\subsection{Intrapersonal Factors}

For many of the participants in this study, their preparation to disclose illustrates a certain level of introspective reflection. More specifically, this reflection involves the discloser performing an assessment in which he/she is able to view their position in relation to the rest of the group.

Brittany's preparation to disclose was a lengthy process - one that required that the majority of the class. Before she chose to disclosure, Brittany underwent a period of self-discovery. She did this by comparing the validity of her experience with those of others who decided to share:

"Well I didn't really share until the very end of the class because I didn't feel like—in a way-I didn't have room to share because it happened to me so long ago and it seemed what we were talking about was so current and it was just-I felt like, "oh it was only when I was 7, 5 or 6 that this happened to me. Other women are getting abused right now so who am I to say anything" and then as the class period went on I realized that this is really important to share so that people can understand who I am.” (Middle Eastern female) 
It appears that Brittany sought confirmation of the relevance of her experience in relation to the rest of the group. This justification proved critical in her preparation to disclose.

Similar to Brittany, the disclosures made by others influenced Marissa's preparation to disclose. When asked if the risk of being viewed negatively by others upon disclosure affected her decision to disclose, Marissa answered in the following way:

"It didn't affect my willingness to disclose but it did affect how much I was willing to disclose." (white female)

Marissa goes on to explain how she viewed herself as just one of many victims of sexual abuse, so when it came time for her to share she didn't feel the need to offer specifics (or what she suggests would drag out the process):

"It affected when I said that I was raped, it affected the way that I said it, it was short, like three bullet points and I'm done. I didn't want to be emotional about it, and I wondered... if I would have given more details. Also what was in my mind was just the fact that we had gone through 1, 2, 3, they're heart wrenching you know. People feel pity for you, they feel bad for you, and I just didn't want to; we had already done it three times, so I was like, let's just speed this along. I didn't want to be like another one." (white female)

This self-censorship performed by Marissa speaks to prevalence of comparing oneself to other disclosers that occurred among participants.

\subsection{Relational Factors}

In the study of these seven individuals who disclosed their experience as victims of sexual abuse, relational factors prove to be the most prevalent factor in an individual's preparation to disclose.

For Marcus, the feeling of validation that accompanied hearing the disclosures of his peers "opened up the door" for him to share:

"Wow, it was like, your experiences were like mine, you felt what I felt. That was the amazing thing. It's easier to talk about what's on the surface but to talk about this is what I felt about it, this is how it affected me, this is how it hurt me, that opened up the door for me to feel like I could do that comfortable." (African-American male)

Upon identifying his membership within a group of people with whom he could relate, Marcus gained a sense of comfort. This comfort empowered him with the necessary preparation to make the ultimate decision to disclose.

In Marcus' case, his preparation to disclose involved his concern with how he viewed himself in relation to the rest of the class. He recalls feeling upset by female peers' comments about the inability of men to relate to victims of sexual abuse. He goes on to identify the "trigger" of his disclosure as being his attempt to correct the disconnect between his assumed identity as either a sexual predator and/or simply the inability to relate to victims of sexual abuse, versus his actual experiences and identity as a victim of sexual abuse.

"Hearing that was like, I don't want you to feel that a man can't feel this. Because I feel this; I'm still reeling over it." (African-American male)

It appears that Marcus' preparation to disclose occurred as a result of his desire to correct his peers' views of exclusivity of sexual abuse, as experienced only by women. He wanted his peers to know him. The decision by two males to reveal their own experiences of abuse may have contributed greatly to the cohesiveness of this mixed gender class. If abuse had only occurred with females, it might have set up a we/them dichotomy. Whether or not his decision to disclose was intended for the good of the group, or just for him to "prove" that he could relate to other victims of sexual abuse remains unclear. Nevertheless, his internal reflection appears to have dominated his preparation for disclosure.

Leah's preparation to disclose appears to have arisen from a deep sense of responsibility to the rest of the group of individuals who disclosed:

"I think it was the right thing to do because if, I felt kind of like a liar because since everybody else started talking about it, I felt like if I didn't I'd be mad at myself and then I'd be denying others the opportunity to know they were not alone." (Asian female)

Other participants echoed the feeling of responsibility to the group expressed by Leah. But for Rachel, it appears that the obligation she felt was less about relating to other victims in the class, and instead came more from her understanding of a sense of "give and take" involved in disclosures:

"Yeah I'm still glad I did it. The people who I was closest to were the people I wanted to talk about it. At first 
I wasn't sure and then I did it anyway. I think it helped a lot. I think our relationship is stronger because of that and for one person it was-I already knew crazy stories from his life so I kinda felt like-I should reciprocate; he should know something about me." (white female)

So while individuals' specific preparation process for disclosure may vary in terms of details, it remains clear that the group and group membership plays a central role in the decision making process.

\subsection{Combinational Factors}

Rather than understanding combinational factors as two simultaneously occurring factors, a more accurate description is that the presence of one factor may trigger another factor or that one factor can evolve into another. The dominant combinational factors at work in this study appear to be that of relational/environment factors.

For Rachel, a particular disclosure event resonated with her on a relational level which then had environmental consequences. She says this about a female instructor's disclosure:

"It kind of brought her down to our level. Got rid of the authoritative feeling." (white female)

Rachel appears to have experienced a humanizing of her instructor. This disclosure disrupted the traditional student-teacher power dynamic and created an opportunity for Rachel to experience an environment where she could begin to consider to make her own disclosure.

For Marissa, the combinational factors at work are again relational/environmental in nature. In contrast to Rachel, the factors in Marissa's case for play out much differently. As noted in earlier (p. 7):

"Everyone else was sharing, that made me feel more comfortable. And the expectation was that we were supposed to share, not that I did it to meet anybody's expectations, but what I'm trying to say is that, it wasn't like they were getting something other than what they thought they were going to get. It wasn't left field and it wasn't off topic. So, everybody was sharing; it was really nice to sit around in a group with other females talking about things that most females would understand. The other things that other people were saying, that was very comforting and it made me feel comfortable." (white female)

Marissa first speaks to the environment of sharing with made her feel "more comfortable" to share because people knew what to expect. As she continues to describe this environment of comfort it becomes clear that it was the relationships with others in the class, particularly the females that prepared her to disclose. Because this kind of environment was already established, sharing didn't seem out of context and it created a sense of "comfort” for Marissa.

The emphasis on the personal experiences of students, the inclusion of all students, and the appreciation of what one "other," or "others" who are different, could teach, enhanced a strong and well-established classroom identity. Classroom identity was built upon the principle that personal and emotional learning were central to education.

Students felt an array of emotions immediately upon disclosing their secrets. We provided two coders with the set of feelings provided by Ivey, Ivey \& Zalaquett (2014, p. 182). They list seven major feelings which can have a set of words that would be consistent with these major feelings. For example the major feeling of "sad" can also be expressed as unhappy, blue, dismal, or regret. The two coders examined the interviews and classified the feelings of the seven respondents. There was an $85 \%$ agreement. When there was disagreement, a third coder was called in to resolve the discrepancy.

\section{Findings}

Each of the seven students described at least one positive emotion when reflecting upon disclosing to the class, with five students having more than one. This is significant since the English vocabulary has more words for negative than positive emotions. None of the seven students had completely negative reactions with one student expressing only positive reactions. The most prevalent emotion reported was a sense of purging, with six students stating they felt this way. We coded this as a positive emotion since students in eliminating the burden or sense of shame, felt relief, lightness, or a feeling of wholeness. There were four distinct reactions that were only experienced by one of the individuals in the group. These unique reactions included discomfort, calmness, anxiety and numbness. Of the three students who reported regrets, all of them were able to feel "not alone."

\subsection{Positive Emotions}

The two most prevalent positive responses from students were a sense of "purging” and "realization" that they 
were not the only individuals who had experienced a similar event. Five of seven felt purging and six of the seven felt that they were no longer alone.

The purging seemed to be the strongest and most important reaction. To purge, or to get rid of an unwanted feeling, memory, or condition, was the metaphor students used to explain how they felt while disclosing. One student compared this feeling to the physical experience of vomiting or rather, "when there's something inside of you that's not feeling right and you expel it. In that moment it is very satisfying." Similarly, the students had unwanted feelings and memories, and revealing these feelings and memories wasn't easily done nor was it something that felt right to do. However, once the incident was exposed amongst the group, the students were able to feel mostly positive emotions. Consequently, students felt seventeen positive emotions compared to only ten negative emotions.

As previously mentioned, five out of the seven students described this sense of purging when sharing their secrets. Leah explained,

"When I shared with the classroom it was more like a purging of it, because I felt like everyone else was getting rid of it, or getting rid of the bad emotion. I felt like I was also getting rid of that bad emotion and it served me to think about it in a whole different light." (Asian female)

Leah was a student who had a negative experience when she shared her secrets with her roommates. When she disclosed her secret within the classroom, she, like her five other classmates, did not feel alone since others had a similar experience. Brittany questioned why she had shared his secret in the classroom but later felt the "purging" of the feeling and memory,

“That day was-I was like 'why am I sharing it with so many people?' but once I did share, it allowed me to feel more freedom and it allowed me to really just to take it off my chest, take it off my shoulders because I realized everyone else was carrying the same thing." (African-American female)

Six of the seven students explained that by disclosing in the classroom they realized that they were not alone in their experience. A male student, Brian, clarifies that the main reason as to why he did not leave the classroom after disclosing was because another male in the classroom shared a similar event. He says,

"Just him sitting next to me and he relaying a similar story and just giving each other daps like 'I know what happened. I know how you feel man' that was probably the biggest reason why I didn't just say, "excuse me I gotta get out of here." (white male)

Leah explains that being aware that others in the classroom experienced something similar to her secret assisted her in coping with it:

"I was trying to hide it so much that it took so much of my energy and then when I did share it, it was like other people went through it, so it didn't only happen to me sort of thing, not that it makes it ok but it makes it easier to deal with it." (Asian female)

\subsection{Negative Emotions}

The most frequent negative emotions that the students reported feeling were regret, shame and embarrassment. Three of the students felt regret, the single most common negative emotion felt by the students. Of the three students who felt regret while disclosing, one student felt an immediate feeling of relief after she disclosed. Rachel, said:

"I was still thinking about the same stuff while I was talking. And obviously when you talk about it you kinda jump back and think about it and kinda relive it but then you're kinda like, 'Oh god I don't want to talk about this' but I was at a point where I started talking about it and wanted to turn back and not talk about it but I was already talking about it" (white female)

Even though she started to feel regret and did not want to talk about the incident, Rachel goes on to explain:

"Afterward I felt a culmination of relief, kinda disappointed that I didn't disclose everything." (white female)

Here, the negative emotion of regret was later superseded with the sense of purging. Rachel released the negative feelings inside her, and while hesitant at first, she felt relieved after she expelled it. For students like Jasmine and Brian, others' comments and stories helped them overcome the feeling of regret. Brian's feeling of regret vanished once another male in the class shared a similar experience, instantly creating a bond that neither had before. Jasmine, who felt regret and was uncomfortable also reported that she was not alone. Jasmine later went on to further deal with her revelation and explained that she regretted sharing because it became, as she explains, "a burden and assignment that I had to deal with.” Her feeling of regret was because the event instantly 
became a reality the moment she shared with the class and couldn't continue to suppress the memory in the back of her mind, it became "this problem that had to be solved." After sharing Jasmine began seeing a therapist who helped her confront and solve this problem and states that after "dealing with it" she doesn't have that feeling of regret.

Reacting to the shame he felt upon sharing his secrets, Marcus reported,

"I remember that after I said it, I couldn't look at anybody. I remember averting my eyes and finding spots to look at because I couldn't look at anybody" (African-American male)

When asked how he felt after seeing that some classmates were crying Marcus replied,

"I didn't have to advert my gaze from them. To see concern, to see them with compassion, to see them with love coming from their faces, it wasn't what I expected. To a large degree, it freed me up, it was a very important first step." (African-American male)

His comments suggest that the shame resulted in his ability to see himself differently because his classmates were now looking at him with a sense of understanding and empathy rather than judgment. In reviewing the students' feelings towards immediately disclosing, we find that students' negative feelings are most commonly offset by an outside source- either one or more other students disclosing a similar event.

\section{Discussion}

The evidence from this small sample of college students points towards the positive benefits of disclosing deep secrets in a classroom. The guilt and shame that all students carried with them about their sexual abuse was revealed and responded to in a supportive and accepting manner. No student felt judged. There were two major reactions to the revelation of these secrets. One student recognized that confronting her past in a public setting would not be sufficient for dealing with her shame and began seeing a therapist. Another student, after discussing her secret with the class, felt that she could tell her boyfriend about her experience. He did not respond with sympathy and felt they needed to break up. This student also reported there had been problems in the relationship prior to her revelation and was not convinced that her secret was the cause. Promises of anonymity in a college classroom cannot be guaranteed. There are certainly risks involved for disclosers of such deeply intimate revelations. The choice made by the instructors was that the risks involved would led to gains that might be lost if students continued to carry the twin burdens of guilt and shame.

\section{Conclusion}

The process of disclosing was significantly related to the two factors of environment ("classroom”) and relationships. Revealing the secrets of abuse and assault led to relief and satisfaction as students discovered that others have had a similar experience and that others did not judge. By sharing a secret, students learned that they were not alone which led to a very potent, positive emotion. Our study has argued that 1 ) creating a safe space for students in a classroom, 2) providing students with diverse professors, 3) instructors who model by self-disclosure, and 4) encouraging revelations about race and sexism and sexual identity can lead to the expression of the deeper secrets about abuse. This expression seems to have resulted in important positive feelings for participants as well as to a more cohesive class environment. Every student except one expressed positive feelings. Even with the initial concern of embarrassment, the purging led to relief, a feeling of wholeness, and lightness. The single negative consequence of self-disclosure occurred in an intimate relationship where there had been prior difficulties. Bishop's concerns about guarantees for trust were addressed by students who cited identification with an instructor, a feeling of "we-ness" with other classmates, and prior revelations about racism. Whether self-disclosures with guarantees of trust can be done in larger classes remain a question. Research with larger samples, as well as more diverse populations, and the detailed description of the classroom format will be necessary to determine the limits and consequences of self-disclosure. This small sample that included men and women of multiple ethnicities and races in a classroom that emphasized openness and self-examination in conjunction with the theoretically important idea of secrets, confirmed the value of self-disclosure.

\section{References}

Alcoholics Anonymous (1990). The AA Group: Where It All Begins. New York, NY: AA Grapevine.

Bishop, N. (1996). Trust Is Not Enough: Classroom Self-Disclosure and the Loss of Private Lives. Journal of Philosophy of education, 30, 429-439. http://dx.doi.org/10.1111/j.1467-9752.1996.tb00411.x 
Dhillon, M., Moore, J., Rabow, J., \& Vega, Y. M. (2013). First You Stand Out, Then You Stand up: Becoming an Ally for the LGBT Community. Sociology Mind, 3, 333-338. http://dx.doi.org/10.4236/sm.2013.34045

Dhillon, M., Rabow, J., Han, V., Maltz, S., \& Moore, J. (2014). Achieving Consciousness and Transformation in the Classroom: Race, Gender, Sexual Orientations and Social Justice. Sociology Mind, 5, 74-83. http://dx.doi.org/10.4236/sm.2015.52008

Dindia, K., \& Allen, M. (1992). Sex Differences in Self-Disclosure: A Meta-Analysis. Psychological Bulletin, 112, $106-124$. http://dx.doi.org/10.4236/sm.2015.52008

Empey, L.T., \& Rabow, J. (1961). The Provo Experiment in Delinquency Rehabilitation. American Sociological Review, 26, 679-295. http://dx.doi.org/10.2307/2090198

Frattaroli, J. (2006). Experimental Disclosure and Its Moderators: A Meta-Analysis. Psychological Bulletin, 132, 823-865. http://dx.doi.org/10.1037/0033-2909.132.6.823

Frijns, T., \& Finkenauer, C. (2009). Longitudinal Associations between Keeping a Secret and Psychosocial Adjustment in Adolescence. International Journal of Behavioral Development, 33, 145-154.

http://dx.doi.org/10.1177/0165025408098020

Goffman, E. (1959). The Presentation of Self in Everyday Life. Garden City: Doubleday.

Grambling, L. F., Carr, R. L., \& McCain, N. L. (2000) Family Responses to Disclosure of Self-as-Lesbian. Issues in Mental Health Nursing, 21, 653-669. http://dx.doi.org/10.1080/01612840050207590

Han, V., Philyaw, Z., \& Rabow, J. (2015). Theorists of Transformation Pedagogy. International Journal of Humanities Social Sciences and Education (IJHSSE), 2, 24-33.

Hébert, M., Tourigny, M., Cyr, M., McDuff, P., \& Joly, J. (2009). Prevalence of Childhood Sexual Abuse and Timing of Disclosure in a Representative Sample of Adults from Quebec. The Canadian Journal of Psychiatry, 54, 631-636.

Ivey, A., Ivey, M. B., \& Zalaquett, C. (2014). Intentional Interviewing and Counseling. Belmont, CA: Cengage Learning.

Loevinger, J., \& Blasi, A. (1976). Ego Development: Conceptions and Theories. San Francisco: Jossey-Bass.

Marx, K. (1899). Secret Diplomatic History of the Eighteenth Century. Ed. Eleanor Marx Aveling. London, UK: Swan Sonnenschien \& Co., Limited.

Rabow, J., \& Yeghnazar, P. (2009a). Transformative Teaching in the University: Uncovering and Confronting Racism, Sexism and Homophobia. Teaching Race and Ethnicity in Higher Education: Perspectives from North America. Birmingham: University of Birmingham.

Rabow, J., \& Yeghnazar, P. (2009b). A Guide to Learning through Discussion: For Students. San Diego, CA: University Readers, Inc.

Rabow, J., Dhillon, M., \& Payne, K. E. (2015) “Pink Triangle Experience Exercise.” Assignment, Class Activity Published in TRAILS: Teaching Resources and Innovations Library for Sociology. Washington DC: American Sociological Association. http://trails.asanet.org

Rosenbloom, S. R., \& Fetner, T. (2001). Sharing Secrets Slowly: Issues of Classroom Self-Disclosure Raised by Student Sex Workers. Teaching Sociology, 29, 439-453. http://dx.doi.org/10.2307/1318945

Simmel, G. (1906). The Sociology of Secrecy and of Secret Societies. The American Journal of Sociology, 11, 441-498. http://dx.doi.org/10.1086/211418

Slepian, M. L., Masicampo, E. J., Toosi, N. R., \& Ambady, N. (2012). The Physical Burdens of Secrecy. Journal of Experimental Psychology: General, 141, 619-624. http://dx.doi.org/10.1037/a0027598

Sorsoli, L., Kia-Keating, M., \& Grossman, F. K. (2008). “I Keep That Hush-Hush”: Male Survivors of Sexual Abuse and the Challenges of Disclosure. Journal of Counseling Psychology, 55, 333-345. http://dx.doi.org/10.1037/0022-0167.55.3.333

Weber, M. (2002). The Protestant Ethic and the Spirit of Capitalism: and Other Writings. Penguin.

Won-Doornink, M. J. (1985). Self-Disclosure and Reciprocity in Conversation: A Cross National Study. Social Psychology Quarterly, 48, 97-107. http://dx.doi.org/10.2307/3033605 


\section{Submit or recommend next manuscript to SCIRP and we will provide best service for you:}

Accepting pre-submission inquiries through Email, Facebook, Linkedin, Twitter, etc A wide selection of journals (inclusive of 9 subjects, more than 200 journals)

Providing a 24-hour high-quality service

User-friendly online submission system

Fair and swift peer-review system

Efficient typesetting and proofreading procedure

Display of the result of downloads and visits, as well as the number of cited articles

Maximum dissemination of your research work

Submit your manuscript at: http://papersubmission.scirp.org/ 